\title{
Idiopathic bronchiolitis obliterans organizing pneumonia with multiple cavitary lung nodules
}

\author{
M. Haro, M. Vizcaya, A. Texidó, X. Aguilar, M. Arevalo
}

\begin{abstract}
Idiopathic bronchiolitis obliterans organizing pneumonia with multiple cavitary lung nodules. M. Haro, M. Vizcaya, A. Texidó, X. Aguilar, M. Arevalo. (CERS Journals Ltd 1995.
\end{abstract}

ABSTRACT: Bronchiolitis obliterans organizing pneumonia (BOOP) is a pulmonary disorder with a wide spectrum of radiological features.

We report the case of a 58 year old woman, in whom the radiological appearance was multiple cavitary nodules in both lungs, that responded with a complete resolution after corticosteroid therapy.

This finding justifies the inclusion of BOOP in the differential diagnosis of multiple cavitary nodules.

Eur Respir J., 1995, 8, 1975-1977.
Sección de Neumología, Hospital General, Albacete, Spain.

Correspondence: M. Haro Estarriol

Sección de Neumología (Planta 2), Hospital General, c/Hermanos Falcó, s/n, 02006 - Albacete, Spain.

Keywords: Bronchiolitis obliterans organising pneumonia, multiple cavitary nodules Received: December 281994

Accepted after revision May 81995
Bronchiolitis obliterans organizing pneumonia (BOOP) is an independent clinicopathological entity which emerged in the 1980s, especially after the reports by DAVIDSON [1] and EPLER [2], and is defined histopathologically as granulation tissue plugs within the lumens of small airways, sometimes completely obstructing them, and granulation tissue extending into alveolar ducts and alveoli [1-3]. Early recognition of BOOP is very important, due to the good prognosis when it is treated. However, rare clinical or radiological findings may make diagnosis difficult $[3,4]$. We report an atypical case of BOOP presenting as multiple cavitary nodules in both lungs.

\section{Case report}

A 58 year old, nonsmoking, white woman was admitted to the hospital because of multiple nodules on chest radiograph (fig. 1). She had a history of high fever, weakness and cough of 2 months duration. Physical examination was normal. The erythrocyte sedimentation rate was $124 \mathrm{~mm} \cdot \mathrm{h}^{-1}$, haemoglobin $11.7 \mathrm{mmol} \cdot \mathrm{L}^{-1}$, haematocrit $37 \%$, and white cell count $5.8 \times 10^{9} \cdot \mathrm{L}^{-1}\left(5,800\right.$ cells $\left.\cdot \mathrm{mm}^{-3}\right)$ with $64 \%$ neutrophils, $21 \%$ lymphocytes, $12 \%$ monocytes and $2 \%$ eosinophils. The aspartate aminotransferase (AST) level was $32 \mathrm{U} \cdot \mathrm{L}^{-1}$, alanine aminotransferase (ALT) 25 $\mathrm{U} \cdot \mathrm{L}^{-1}$, lactate dehydrogenase (LDH) $190 \mathrm{U} \cdot \mathrm{L}^{-1}$, urea nitrogen $22 \mathrm{mg} \cdot \mathrm{dL}^{-1}$, and urine microscopy was normal. Antinuclear antibody and anti-deoxyribonucleic acid (DNA) were positive (1/40 with nucleolar pattern, and $1 / 10$, respectively), with normal complement levels. Rheumatoid factor, antineutrophil cytoplasmatic autoantibodies (ANCA), carcinoembryonic antigen (CEA) and serum angiotensin-converting enzyme (SACE) were normal.

A computed tomographic scan of the thorax and the abdomen revealed only that the multiple lung nodules were cavitated (fig. 2). The electrocardiogram and

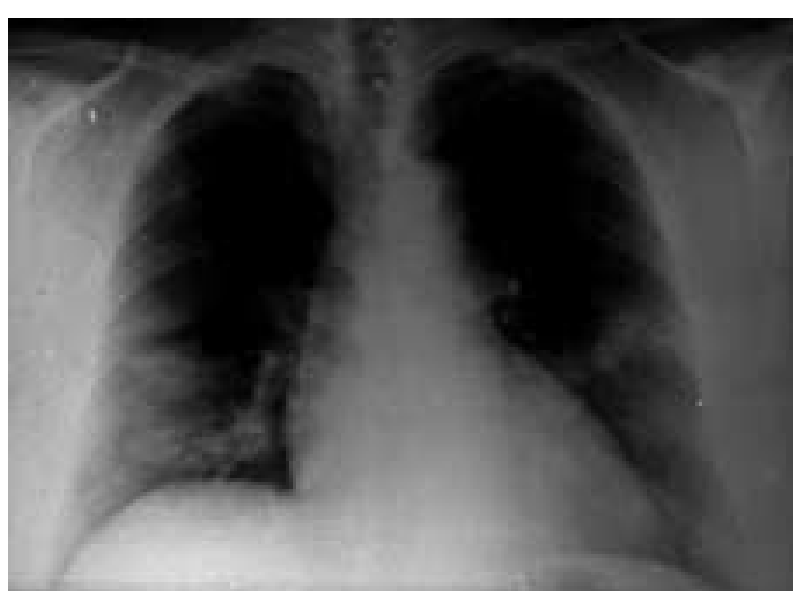

Fig. 1. - Chest radiograph on admission showing multiple bilateral lung nodules.

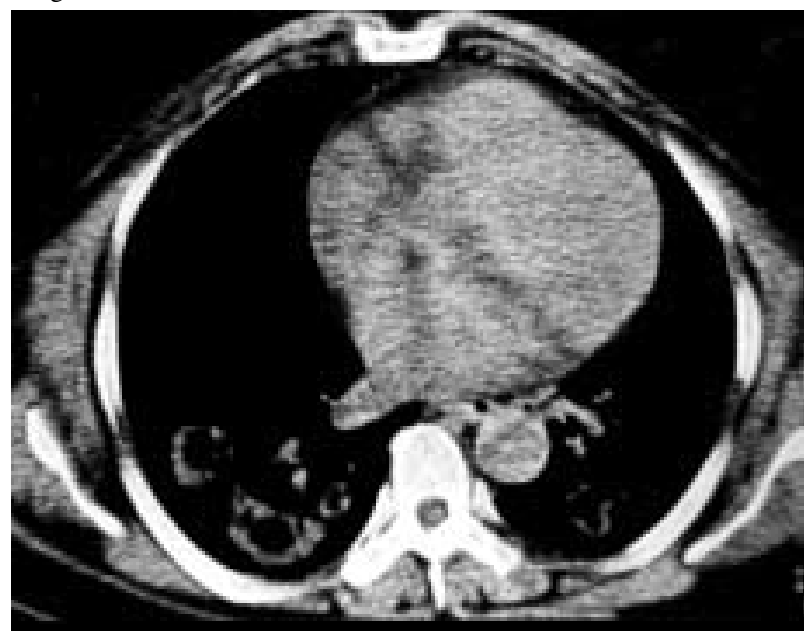

Fig. 2. - Computed tomographic scan of the thorax showing multiple predominantly lower cavitary nodules. 
Table 1. - Pulmonary function studies and arterial blood gas analysis (breathing room air) on admission and 6 months after corticosteroid therapy

\begin{tabular}{|c|c|c|c|c|}
\hline & \multicolumn{2}{|c|}{ On admission } & \multicolumn{2}{|c|}{ After therapy } \\
\hline & Observed & $\begin{array}{c}\text { pred } \\
\%\end{array}$ & Observed & $\begin{array}{c}\text { pred } \\
\%\end{array}$ \\
\hline FVC L & 2.35 & 75 & 2.42 & 79 \\
\hline FEV1 L & 2.12 & 91 & 2.08 & 92 \\
\hline $\mathrm{FEV} 1 / \mathrm{FVC} \%$ & 90 & 124 & 86 & 119 \\
\hline RV L & 1.07 & 65 & 1.42 & 79 \\
\hline TLC L & 3.58 & 77 & 3.80 & 82 \\
\hline$T \mathrm{~L}, \mathrm{CO}$ & & 98 & & 91 \\
\hline $\mathrm{S}_{\mathrm{a}, \mathrm{O}_{2}} \quad \%$ & 93 & & 96 & \\
\hline $\begin{array}{ll}P_{\mathrm{a}, \mathrm{O}_{2}} & \mathrm{kPa} \\
& \mathrm{mmHg}\end{array}$ & $\begin{array}{c}10.5 \\
79\end{array}$ & & $\begin{array}{c}11.3 \\
85\end{array}$ & \\
\hline $\begin{array}{rl}\mathrm{Pa}_{\mathrm{a}, \mathrm{CO}_{2}} & \mathrm{kPa} \\
\mathrm{mmHg}\end{array}$ & $\begin{array}{l}4.9 \\
37\end{array}$ & & $\begin{array}{l}5.2 \\
40\end{array}$ & \\
\hline
\end{tabular}

FVC: forced vital capacity; FEV1: forced expiratory volume in one second; RV: residual volume; TLC: total lung capacity; TLCO: transfer factor of the lungs for carbon monoxide; $\mathrm{S}_{\mathrm{a}, \mathrm{O}_{2}}$ : arterial oxygen saturation; $\mathrm{Pa}, \mathrm{O}_{2}:$ arterial oxygen tension; $\mathrm{Pa}_{\mathrm{a}} \mathrm{CO}_{2}$ : arterial carbon dioxide tension; $\%$ pred: percentage of predicted value.

ultrasound examination of the heart and abdomen were normal. A tuberculin skin test was negative. The results of pulmonary function tests and arterial blood gas analysis are presented in table 1.

Bronchoscopic examination showed a normal appearance without endobronchial lesions. Bronchoalveolar lavage (BAL) was performed in the right middle lobe and revealed an increased cell count $\left(28 \times 10^{6}\right.$ cells $\cdot \mathrm{dL}^{-1}$ BAL fluid), with an increased percentage of lymphocytes (39\%) and neutrophils (20\%). Microscopic and cytological examination of BAL and bronchial washings revealed no acid-fast bacilli, fungi or atypical cells. Transbronchial lung biopsy of the right lower lobe revealed a pattern of nonspecific organizing alveolar injury. Examination of a transthoracic needle-aspiration biopsy specimen of one of the cavitary lesions was compatible with an inflammatory process.

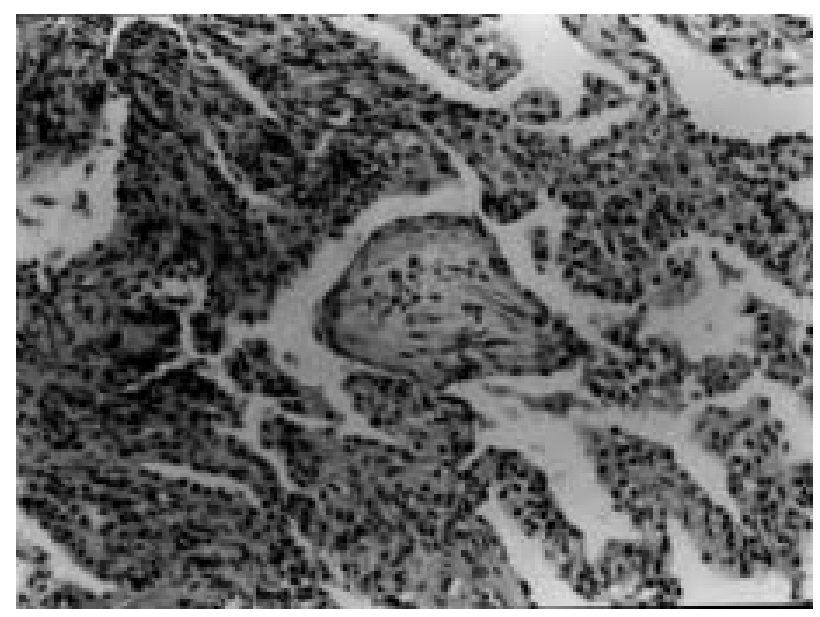

Fig. 3. - Lung biopsy. Plug of granulation tissue extending into alveoli (original magnification $\times 200$ ).
The diagnosis of malignancy was questioned and open lung biopsy was performed. Histopathological examination of the biopsy showed granulation tissue plugs extending into distal alveolar ducts, alveoli and the lumens of small airways, without vasculitis and with negative bacteriological studies (fig. 3).

All of these features led to the diagnosis of BOOP. Prednisone was initiated as a single oral dose $\left(1.5 \mathrm{mg} \cdot \mathrm{kg}^{-1}\right.$ q.d.) for 6 weeks and, when the patient was stable, gradually tapered to zero after a 6 month period, with full pulmonary functional recovery (table 1 ) and normal chest radiograph.

\section{Discussion}

The diagnosis of idiopathic BOOP is usually suggested by radiological findings and confirmed by an open or transbronchial pulmonary biopsy specimen. Recently, these features have been classified into three groups: multiple alveolar patchy opacities; solitary focal pneumonia; and diffuse pulmonary involvement with interstitial pattern [4]. Other patterns may occur, but are rare and raise the suspicion of more common causes. These rare patterns include: concurrent pleural thickening or effusion in addition to patchy infiltrates (including eosinophilic effusion) [5], solitary pulmonary nodule [6], diffuse small nodular opacities [3]; and cavities [2, 3, 7].

The study by EPLER et al. [2] described the first radiographic cavities in 2 of 50 patients with BOOP. In the 9 yrs since they were published, other unusual cases have been detailed, including a cavitated small solitary pulmonary nodule or diffuse opacities with cavitation [6-8]. To our knowledge, this is the first reported case of idiopathic BOOP in which the radiologic presentation was multiple cavitary lung nodules. This finding amplifies the broad radiological spectrum of this entity and justifies the inclusion of idiopathic BOOP in the differential diagnosis of multiple cavitary nodules. Although metastatic carcinoma is the commonest cause of multiple nodular lesions in the lungs and cavitation occurs in 5-10\% of these cases, multiple nodules are not always a sign of malignant disease and benign lesions should be part of the differential diagnosis, as they have been reported in tuberculosis, fungal and parasitic infections, noninfectious granulomatosis (sarcoidosis, Wegener's granulomatosis or rheumatoid nodules) and other unusual cases, such as bleomycin toxicity $[6,9]$.

\section{References}

1. Davidson AG, Heard BE, McAllister WAC, Turner MEH. Cytogenic organizing pneumonitis. Q J Med 1983; 52: 382-394.

2. Epler GR, Colby TV, McLoud TC, Carrington CB, Gaensler EA. Bronchiolitis obliterans organizing pneumonia. N Engl J Med 1985; 312: 152-158.

3. S. John RC, Dorinsky PM. Cryptogenic bronchiolitis. Clin Chest Med 1993; 14: 667-676.

4. King TE. Bronchiolitis. In :Schwartz MI, ed. Interstitial 
Lung Disease. St Louis, Mosby Year Book, 1993; pp. 463495.

5. Aguilar X, Vizcaya M, Texidó Alix A. Eosinophilic pleural effusion associated to BOOP. Med Clin 1993; 102: 516.

6. Domingo JA, Pérez JI, Carretero JA, Ferando J, Cay A, Civeira F. Bronchiolitis obliterans organizing pneumonia: an unusual cause of solitary nodule. Chest 1993; 103: 16211623.

7. Alegre J, Fernández T, Garcia F, Falcó V, Martínez-Vázquez
JM. Three causes of idiopathic BOOP. Eur Respir J 1991; 4: 902-904.

8. Cordier JF, Loire R, Brune J. Idiopathic bronchiolitis obliterans organizing pneumonia: definition and characteristics clinical profiles in a series of 16 patients. Chest 1989; 96: 999-1004.

9. Santrach PJ, Askin FB, Wells RJ, Azizkhan RG, Merten DF. Nodular form of bleomycin-related pulmonary injury in patients with osteogenic sarcoma. Cancer 1989; 64: 806-811. 